Communications in Physics, Vol.24, No.3S2 (2014), pp. 1-7

DOI:10.15625/0868-3166/24/3S2/5013

\title{
PROTON INDUCED X-RAY EMISSION (PIXE) ANALYSIS ON THICK SAMPLES AT HUS 5SDH-2 TANDEM ACCELERATOR SYSTEM
}

\author{
LE HONG KHIEM \\ Institute of Physics, Vietnam Academy of Science and Technology \\ NGUYEN THE NGHIA, VI HO PHONG, AND BUI VAN LOAT \\ Department of Nuclear Physics, Faculty of Physics, Hanoi University of Science, Vietnam \\ National University, Hanoi, Vietnam \\ E-mail:1hkiem@iop.vast.ac.vn
}

Received 20 June 2014

Accepted for publication 20 August 2014

\begin{abstract}
The main purpose of this work is to establish a method of elemental analysis by Proton-Induced X-ray Emission (PIXE) technique on thick samples. Our study has been carried out at Hanoi University of Science (HUS) using a 5SDH-2 Tandem accelerator. The X-ray spectra were measured by a Si(Li) detector $(F W H M=139 \mathrm{eV}$ at $5.9 \mathrm{keV}$ ) and analyzed off-line using GUPIX software. The validity of the proposed method has been checked through its application to NIST standard samples. The concentrations of the elements have been determined in the standard samples are in agreement with the certified values within the error limits. Our method is now used for the analysis of environmental samples at our laboratory.
\end{abstract}

Keywords: PIXE, Pelletron.

\section{INTRODUCTION}

Among other analytical techniques, PIXE is a highly sensitive, multi-elemental analytical technique which is already proved in all prospective areas such as thin films, water, air, archaeological and biological samples etc. Nowadays, PIXE has been widely and successfully used in many areas. At Hanoi university of Science, a 5SDH-2 tandem accelerator system was installed in 2011. This is the first accelerator in Vietnam can be used for the elemental concentration analysis using charged particles, including the PIXE. The system consists of two ion sources, a $1.7 \mathrm{MV}$ tandem accelerator. PIXE elemental analysis is one among many applications can be done using this accelerator.

PIXE analysis is based on the excitation of characteristic X-rays by $\mathrm{MeV}$ proton beam. An energy spectrum of emitted $\mathrm{X}$-ray is recorded by $\mathrm{Si}(\mathrm{Li})$ detector. The elements in the sample are identified from the energies of the characteristic peaks in the $\mathrm{x}$-ray emission spectrum. The quantity of a particular element in the sample is determined from the intensity of its characteristic $\mathrm{x}$-ray emission spectrum.

(C)2014 Vietnam Academy of Science and Technology 
In this report, we attempt to demonstrate the ability of our system for quantitative elemental analysis using thick target proton induced X-ray emission (TTPIXE) technique. The configuration of the system used for this technique is described. For quality assurance and step by step improvement of the accuracy of the method, a procedure was applied for a series of NIST standard samples that are available in our laboratory. This procedure has been successfully applied to some environmental samples that will be presented in this report.

PIXE analysis of thick target is often more complicated than that of thin target. It involves matrix effects when impinged protons lose their energy in the sample and the X-ray emissions at a certain point of the beam path are attenuated. The formula of X-ray intensity of $\mathrm{K}$ shell case for PIXE thick target can be described as [2]:

$$
I(Z)=\frac{N_{a v} \omega_{z} b_{z} \Omega \varepsilon_{z}^{i} t_{z} N_{p} C_{z}}{A_{Z}} \times \int_{E_{0}}^{0} \frac{\sigma_{Z}(E) \exp \left\{-\left(\frac{\mu}{\rho}\right) \frac{\cos \alpha}{\sin \theta_{T O}} \int_{E_{0}}^{0} \frac{d E}{S(E)}\right\}}{S(E)}
$$

where $I(Z)$ is the intensity of a particular K X-ray line, $\sigma_{Z}(E)$ is the ionization cross-section for the $K$ shell, and $N_{p}$ is the number of protons of energy $E_{0}$ incident at angle $\alpha$ to the normal of sample; $\omega_{Z}$ is the corresponding fluorescence yield, and $b_{Z}$ is the fraction of $K X$-rays in the selected line; $N_{a v}$ is Avogadro's number; $S(E)$ is the proton stopping power; $A_{Z}$ is the atomic mass of element $Z ; \theta_{T O}$ is the X-ray take-off angle; $\Omega \varepsilon_{z}^{i}$ is the absolute efficiency of detection, which involves both $\mathrm{X}$-ray detector solid angle and intrinsic efficiency of the silicon detector; $t_{z}$ is the attenuation of the X-rays in any absorber placed between sample and detector; $\frac{\mu}{\rho}$ is the attenuation coefficient within the sample matrix for the X-ray line of interest.

Determination of concentration is quite straightforward when the concentrations of major elements in the sample are known. However, in case of unknown matrix composition, some procedures have to be applied to determine the matrix composition such as the use of a PIXE analysis tuned for determination of major elements or the use of "interactive solution" approach as described in [3]. It should be noted that the matrix effect can be neglected with the use of internal standards.

\section{EXPERIMENT}

\section{II.1. Experiment setup}

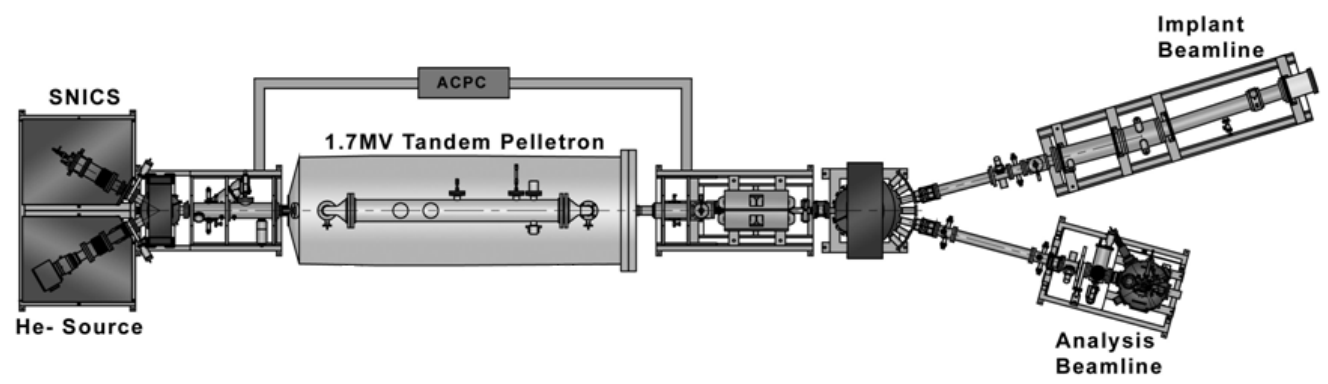

Fig. 1. The schematic of the Pelletron accelerator 1.7 MV model 5SDH-2 
A proton beam, accelerated by the 5SDH-2 tandem accelerator at HUS was used for the present study. The schematic of the system is presented in Fig. 1. Proton beam is produced by a standard radio frequency ion source. After passing through the tandem accelerator tank, maximum proton energy of $3.4 \mathrm{MeV}$ can be obtained. PIXE analysis was performed using analysis beam line and a standard chamber which is located at the end of the beam line. The vacuum inside the chamber is about $10^{-6}$ torr during analysis. The sample holder is at zero degree to the beam direction. Multiple samples can be inserted into an analytical chamber via load lock and oriented with respect to the beam with a five axis manipulator. A Silicon Drift Detector (SDD) with a resolution of $139 \mathrm{eV}$ at $5.9 \mathrm{keV}$, which is connected to a multi-channel analyzer through a conventional electronic chain, was placed at $32.8^{\circ}$ to the beam direction. In Fig. 2, the schematic diagram of the analytical chamber and its associated electronics for X-ray spectroscopy are shown.

In our study for each sample, two proton beams were used. The first beam has energy of $831 \mathrm{keV}$ and the second beam has energy of $2618 \mathrm{keV}$. In both cases, the intensity of the beams was $6 \mathrm{nA}$. For $831 \mathrm{keV}$ proton beam, a thin $12.8 \mu \mathrm{m}$ Kapton absorber foil was put in front of the detector. For $2618 \mathrm{keV}$ proton beam, a $100 \mu \mathrm{m}$ Mylar absorber foil was used. These foils were used to reduce the high intensity low-energy X-rays in the spectra due to light elements as well as to stop the back-scattered protons and thus to improve the analytical sensitivity.

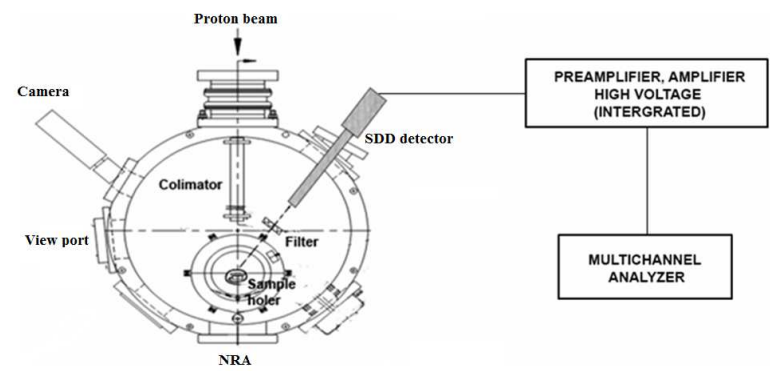

Fig. 2. An overview of the analytical chamber and its set-up for PIXE analysis.

For PIXE quantitative analysis, the exact value of the total charge that arrived at the sample is essential. According to the original design of the chamber, the entire of analytical chamber is electrically isolated and the integrated charge on the samples was collected using a current integrator. This gives us an absolute beam current value. However, currently we are not using this method due to some technical difficulties. To obtain the absolute value of beam intensity, we did a calibration by using standard samples.

\section{II.2. Sample preparation}

In order to check the PIXE analysis method using the thick sample, two standard samples named NIST-611 and NIST-613 were prepared. The standard samples were putted into the glass support, which has a nominal composition of $72 \%$ of $\mathrm{SiO} 2,14 \%$ of $\mathrm{Na}_{2} \mathrm{O}, 12 \%$ of $\mathrm{CaO}$, and $2 \%$ of $\mathrm{Al}_{2} \mathrm{O}_{3}$ in mass fractions. This composition is similar to the matrix composition of most of geological and environmental samples. The samples are thick enough so that they can fully stop the incoming proton beam. The analyzed samples of soil obtained from Faculty of Environmental Science of HUS were also prepared for analysis in the same way as the standard ones. 


\section{II.3. Data analysis}

GUPIX software was used for the quantitative analysis of the X-ray spectra. The software analyzes PIXE spectra by an algorithm of non-linear least-squares fitting. The concentrations of the elements in the samples are quantitatively calculated from the X-ray characteristic peak areas using the fundamental parameter method. Spectral interferences by escape and summing effects in the X-ray spectra could be automatically resolved by GUPIX. Experimental geometry, information of $\mathrm{Si}(\mathrm{Li})$ detector, absorber thickness, energy of the incident particle and the net charge collected are instrumental parameters required by the program. The formula used by GUPIX for determination of elemental concentrations is as bellow:

$$
C_{z}=\frac{Y(Z, M)}{Y_{l t}(Z, M) \cdot H \cdot Q \cdot \varepsilon_{z} \cdot t_{z}}
$$

where $Y_{1 t}$ is the theoretical intensity or yield per $\mu \mathrm{C}$ of charge per steradian per unit of concentration, $\mathrm{Q}$ is the measured beam charge, $\varepsilon_{Z}$ is the intrinsic efficiency of the SDD detector and $t_{z}$ is the transmission of the respective X-rays through any absorber placed between the detector and the target. $H$ is the instrumental constant that takes into account the correction of beam charge, solid angle, intrinsic efficiency of the detector and the other systematic errors. In general, this parameter can be determined by using the reference samples. In our work, the $\mathrm{H}$ value was assumed to be independent of the X-ray energy (i.e. intrinsic efficiency of the detector calculated by GUPIX is acceptable).

For data analysis, we have mainly followed the $\mathrm{H}$ value method described in $[2,5]$. The PIXE spectra of samples obtained from the first run with $831 \mathrm{keV}$ proton beam was analyzed under the "Iterated matrix solution" option of GUPIX software to determine the major element concentration of the sample. The nominal concentration of an internal standard was used as reference to provide normalization factor for the $\mathrm{H}$ value. The second run with $2618 \mathrm{keV}$ proton beam, which is designed for determining the trace elements of the sample, would use the information of major element concentration as an input for the "Fixed matrix solution" option. An internal standard can also be used to adjust the $H$ value. In our study, this procedure was generally applied for all the samples. However, since they are irradiated under the similar experimental conditions (charge collection, the detector and geometry), the $H$ value obtained in previous measurement can be used for the next one.

\section{RESULTS AND DISCUSSION}

The NIST 611 standard sample was measured first. The PIXE X-ray spectra for low and high energy proton beam are shown in Fig. 3. The spectra contain many overlapping X-ray peaks emitted from more than 50 elements according to the certificate sheet of NIST-611 standard. For the run with $831 \mathrm{keV}$ proton beam, the certified value of concentration of calcium was used to adjust the $\mathrm{H}$ value. For the run with $2618 \mathrm{keV}$ proton beam, the certified concentration value of copper content in the sample was used for the same purpose. The spectrum is then analyzed by GUPIX software.

It is clearly seen from the Table 1 that a good agreement was found for most of elements except some elements such as $\mathrm{Na}, \mathrm{Al}, \mathrm{Ag}, \mathrm{Cd}$. This can be explained by overlapping of very strong peak of $\mathrm{Ca}$ that locates in the region contained $L$ peaks of $\mathrm{Ag}$ and $\mathrm{Cd}$. For $\mathrm{Na}$ and $\mathrm{Al}$, an absorption effect of their characteristic X-ray also plays an important role in increasing the error 

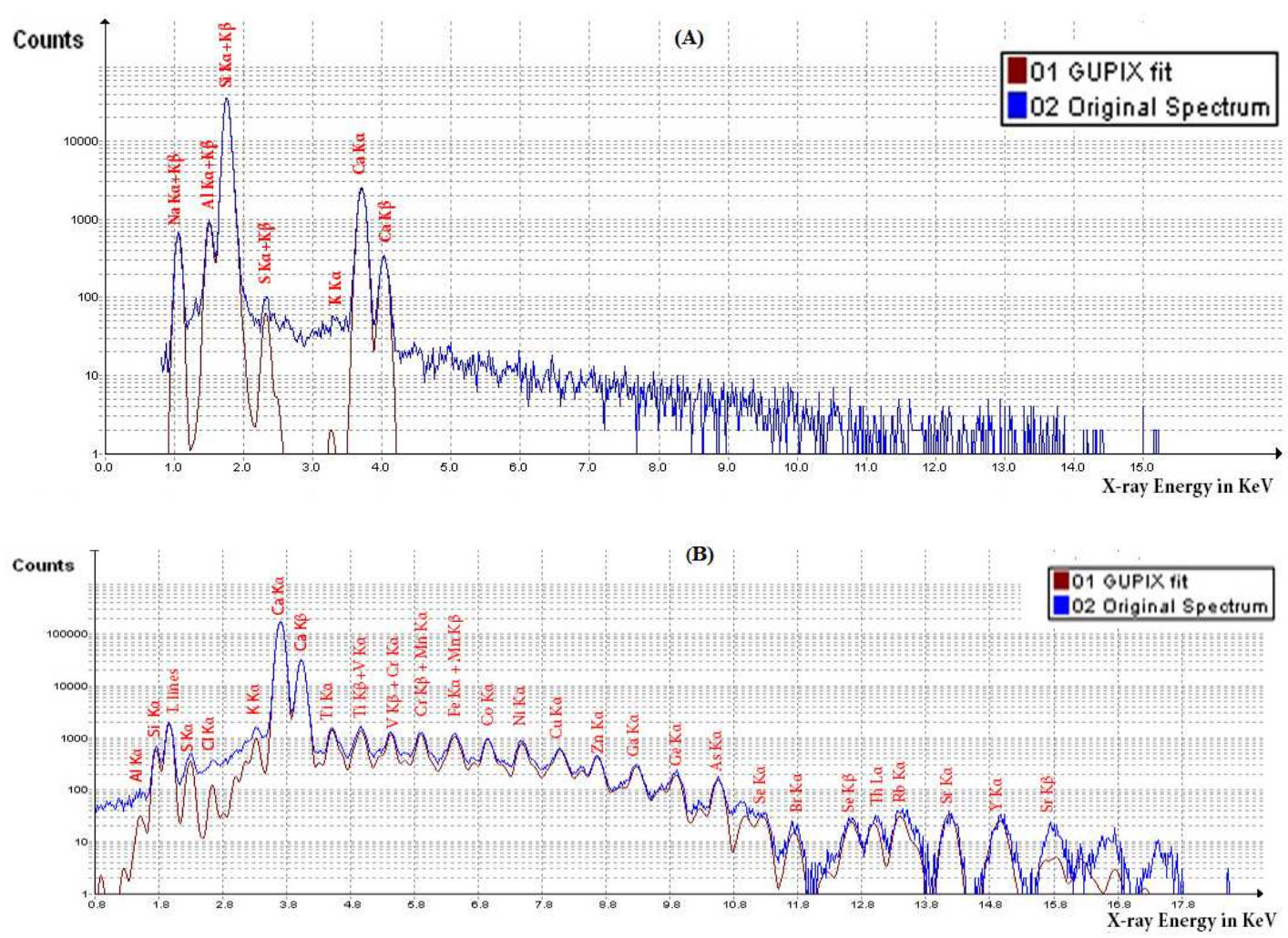

Fig. 3. PIXE spectrum of NIST-611 standard. The sample was irradiated by low energy proton beam $(\mathrm{A})$ and high energy proton beam (B).

of the analysis results due to their low energies. In addition, there are small differences between the obtained values and the certificated ones for $\mathrm{Pb}$, Th and $\mathrm{U}$. These differences might due to small yield of $L_{\alpha}$ peaks emitted from these elements. The effect of pile-up occurred from intense $\mathrm{X}$-ray lines of major elements also plays a role in these discrepancies. Furthermore, the results obtained by two options of data analysis differ less than $6.2 \%$. Therefore, it is concluded that the exact matrix information do not play an important role in the results obtained by GUPIX software.

For the NIST-613 standard sample, the experiment conditions were not changed so that the same $\mathrm{H}$ value, which has been found, can be used. The similar procedure with NIST 611 has been applied and the results are also presented in Table.1. The good agreement between calculated and certificated values has been found, whereas some discrepancies in $\mathrm{Ag}, \mathrm{Cd}, \mathrm{Pb}, \mathrm{Th}, \mathrm{U}$ also observed. The influence of matrix information was introduced to be less than $9.2 \%$.

We applied the same PIXE analysis to a soil sample. The previous $\mathrm{H}$ value obtained from NIST-611 standard sample was used for each run. The matrix composition that was obtained from the run with low energy proton beam is given to GUPIX for the run with higher energy proton beam. The obtained concentrations as well as other information given by GUPIX are presented in Table 2. 
Table 1. Elemental concentrations determined by TTPIXE in standard samples, compared with nominal values

\begin{tabular}{|c|c|c|c|c|c|c|}
\hline \multirow[b]{2}{*}{$\begin{array}{l}\text { Ele- } \\
\text { ment }\end{array}$} & \multicolumn{3}{|c|}{ NIST SRM 611} & \multicolumn{3}{|c|}{ NIST SRM 613} \\
\hline & $\begin{array}{l}\text { Measured } \\
\text { (with exact } \\
\text { matrix) }\end{array}$ & $\begin{array}{l}\text { Mesured } \\
\text { (matrix } \\
\text { calculated } \\
\text { from first run) }\end{array}$ & $\begin{array}{l}\text { Certified } \\
\text { concentration }\end{array}$ & $\begin{array}{l}\text { Measured } \\
\text { (with exact } \\
\text { matrix) }\end{array}$ & $\begin{array}{l}\text { Mesured } \\
\text { (matrix } \\
\text { calculated } \\
\text { from first } \\
\text { run) }\end{array}$ & $\begin{array}{l}\text { Certified } \\
\text { concentration }\end{array}$ \\
\hline $\mathrm{Na}^{*}$ & $\begin{array}{l}136692.0 \pm \\
4100.76\end{array}$ & $\begin{array}{l}136692.0 \pm \\
4100.76\end{array}$ & 103848.3692 & $\begin{array}{l}134817.0 \pm \\
4300.66\end{array}$ & $\begin{array}{l}134817.0 \pm \\
4300.66\end{array}$ & $\begin{array}{l}103848.4 \pm \\
0.00\end{array}$ \\
\hline $\mathrm{Al}^{*}$ & $\begin{array}{l}13805.0 \pm \\
310.61\end{array}$ & $\begin{array}{l}13805.0 \pm \\
310.61\end{array}$ & 10585.00685 & $\begin{array}{l}13774.0 \pm \\
336.09\end{array}$ & $\begin{array}{l}13774.0 \pm \\
336.09\end{array}$ & $10585.0 \pm 0.00$ \\
\hline $\mathrm{Si}^{*}$ & $\begin{array}{l}385613.0 \pm \\
1966.63\end{array}$ & $\begin{array}{l}385613.0 \pm \\
1966.63\end{array}$ & 336553.1428 & $\begin{array}{l}365895.0 \pm \\
3256.47\end{array}$ & $\begin{array}{l}365895.0 \pm \\
3256.47\end{array}$ & $\begin{array}{l}336553.1 \pm \\
0.00\end{array}$ \\
\hline K & $<41.9$ & $<45.4$ & 64 & $420.0 \pm 34.48$ & $444.0 \pm 36.45$ & $461.0 \pm 0.00$ \\
\hline $\mathrm{Ca}^{* *}$ & $\begin{array}{l}85728.0 \pm \\
600.10\end{array}$ & $\begin{array}{l}85728.0 \pm \\
600.10\end{array}$ & 85762.892 & $\begin{array}{l}85730.0 \pm \\
934.46\end{array}$ & $\begin{array}{l}85730.0 \pm \\
934.46\end{array}$ & $85762.9 \pm 0.00$ \\
\hline $\mathrm{Ti}$ & $31.0 \pm 6.29$ & $32.5 \pm 6.60$ & $50.1 \pm 0.80$ & $448.1 \pm 14.12$ & $463.1 \pm 14.59$ & $437.0 \pm 0.00$ \\
\hline $\mathrm{Cr}$ & $26.7 \pm 5.02$ & $27.6 \pm 5.20$ & $29.9 \pm 4.20$ & $407.9 \pm 14.52$ & $416.9 \pm 14.88$ & $415.0 \pm 29.00$ \\
\hline $\mathrm{Mn}$ & $37.1 \pm 5.07$ & $38.2 \pm 5.15$ & $37.7 \pm 3.80$ & $420.1 \pm 14.87$ & $427.6 \pm 15.14$ & $457.0 \pm 55.00$ \\
\hline $\mathrm{Fe}$ & $51.5 \pm 3.89$ & $52.5 \pm 3.97$ & $51.0 \pm 2.00$ & $469.2 \pm 11.03$ & $475.6 \pm 11.18$ & $458.0 \pm 9.00$ \\
\hline Co & $38.0 \pm 6.90$ & $38.9 \pm 7.00$ & $35.5 \pm 1.20$ & $367.1 \pm 20.15$ & $371.5 \pm 20.32$ & $390.0 \pm 0.00$ \\
\hline $\mathrm{Ni}$ & $49.0 \pm 6.80$ & $49.7 \pm 6.87$ & $38.8 \pm 0.20$ & $392.6 \pm 17.04$ & $394.3 \pm 17.15$ & $458.7 \pm 4.00$ \\
\hline $\mathrm{Cu}^{* *}$ & $26.0 \pm 5.14$ & $26.3 \pm 5.18$ & $37.7 \pm 0.90$ & $444.0 \pm 17.54$ & $445.3 \pm 17.63$ & $444.0 \pm 4.00$ \\
\hline $\mathrm{Zn}$ & $43.4 \pm 7.06$ & $43.7 \pm 7.08$ & & $419.2 \pm 19.74$ & $420.3 \pm 19.75$ & $433.0 \pm 0.00$ \\
\hline As & $29.0 \pm 7.17$ & $29.0 \pm 7.11$ & $37.4 \pm 0.00$ & $236.4 \pm 17.66$ & $235.7 \pm 17.58$ & $340.0 \pm 20.00$ \\
\hline $\mathrm{Se}$ & $14.0 \pm 4.99$ & $13.9 \pm 4.98$ & $16.1 \pm 1.60$ & $88.0 \pm 15.49$ & $87.7 \pm 15.44$ & $115.2 \pm 2.20$ \\
\hline $\mathrm{Rb}$ & $12.0 \pm 9.68$ & $11.9 \pm 9.61$ & $31.4 \pm 0.40$ & $364.8 \pm 35.02$ & $362.8 \pm 34.90$ & $425.7 \pm 0.80$ \\
\hline $\mathrm{Sr}$ & $73.7 \pm 16.62$ & $73.3 \pm 16.52$ & $78.4 \pm 0.20$ & $482.6 \pm 38.70$ & $479.4 \pm 38.45$ & $515.5 \pm 0.50$ \\
\hline $\mathrm{Ag}$ & $211.1 \pm 88.07$ & $229.4 \pm 95.61$ & $22.0 \pm 0.30$ & $620.1 \pm 108.77$ & $\begin{array}{l}657.6 \pm \\
115.21\end{array}$ & $268.0 \pm 29.00$ \\
\hline $\mathrm{Cd}$ & $212.4 \pm 77.23$ & $229.6 \pm 83.69$ & $29.9 \pm 4.20$ & $485.1 \pm 103.81$ & $\begin{array}{l}513.4 \pm \\
109.82\end{array}$ & $244.0 \pm 22.00$ \\
\hline $\mathrm{Tl}$ & $<21.1$ & $<21.2$ & $15.7 \pm .30$ & $25.7 \pm 22.10$ & $25.4 \pm 22.01$ & $61.8 \pm 2.50$ \\
\hline $\mathrm{Pb}$ & $11.1 \pm 17.54$ & $11.2 \pm 17.50$ & $38.6 \pm .20$ & $332.6 \pm 41.11$ & $331.0 \pm 40.88$ & $426.0 \pm 1.00$ \\
\hline Th & $26.6 \pm 20.22$ & $26.5 \pm 20.07$ & $37.8 \pm .08$ & $571.2 \pm 61.06$ & $568.0 \pm 60.72$ & $457.2 \pm 1.20$ \\
\hline $\mathrm{U}$ & $<40.6$ & $<40.5$ & $37.4 \pm .08$ & $361.5 \pm 62.94$ & $359.4 \pm 62.75$ & $461.5 \pm 1.10$ \\
\hline
\end{tabular}


Table 2. Elemental concentrations determined by TTPIXE in the soil sample.

\begin{tabular}{|c|c|c|c|c|c|}
\hline $\begin{array}{c}\text { Element } \\
+ \text { Principal } \\
\text { line }\end{array}$ & Peak area & Filter transmission (\%) & Concentration (ppm) & Error $(\%)$ & $\begin{array}{l}\text { Detection limit } \\
\quad(\mathrm{ppm})\end{array}$ \\
\hline $\mathrm{NaK}$ & 535.3 & 1.03 & 5747.1 & 6.92 & 618 \\
\hline $\mathrm{MgK}$ & 8956 & 6.441 & 14177.6 & 1.03 & 129 \\
\hline AlK & 62237.9 & 18.291 & 39552.5 & 0.36 & 62.3 \\
\hline $\mathrm{SiK}$ & 436657 & 33.794 & 182272 & 0.13 & 45.9 \\
\hline S K & 11054.5 & 62.032 & 4973.6 & 0.89 & 30.3 \\
\hline $\mathrm{ClK}$ & 2604.2 & 72.069 & 1352.9 & 2.21 & 33.4 \\
\hline K K & 21258.5 & 84.962 & 17194.7 & 0.61 & 40.9 \\
\hline $\mathrm{CaK}$ & 195059 & 88.893 & 221836.2 & 0.2 & 174.5 \\
\hline TiK & 21774.3 & 52.592 & 2781.8 & 0.63 & 8.6 \\
\hline $\mathrm{CrK}$ & 558.3 & 69.15 & 62 & 7.79 & 8.2 \\
\hline $\mathrm{MnK}$ & 4082.8 & 75.268 & 474.4 & 1.63 & 7.5 \\
\hline FeK & 181152 & 80.177 & 22293.7 & 0.2 & 12.7 \\
\hline $\mathrm{CoK}$ & 273.7 & 84.062 & 38.5 & 117.8 & 75.5 \\
\hline $\mathrm{NiK}$ & 222.4 & 87.147 & 35.9 & 25.77 & 17.2 \\
\hline $\mathrm{CuK}$ & 105.4 & 89.592 & 20.8 & 18.35 & 6.7 \\
\hline $\mathrm{ZnK}$ & 269.7 & 91.53 & 63.9 & 7.16 & 4.4 \\
\hline $\mathrm{GeK}$ & 21.7 & 94.303 & 8.3 & 82.85 & 10.7 \\
\hline AsK & 39.8 & 95.29 & 19.5 & 31.88 & 12.3 \\
\hline $\mathrm{RbK}$ & 58 & 97.681 & 88.5 & 17.13 & 22.1 \\
\hline SrK & 333.4 & 98.032 & 691.4 & 6.24 & 41.9 \\
\hline $\mathrm{PbLA}$ & 38.2 & 95.301 & 36.5 & 45.55 & 35.8 \\
\hline
\end{tabular}

\section{CONCLUSION}

PIXE technique proved to be a reliable multi-elemental and high sensitive analytical tool. Thin-target PIXE offers the possibility to determine elemental concentrations without corrections for X-ray self-absorption and proton stopping in target as for the case of thick-target PIXE. However, sample preparation is rather difficult in comparison with the thick sample method. In this work, PIXE analysis on thick samples at HUS tandem accelerator was established and applied successfully in analysis of the environmental samples. The method has been checked by analyzing the elemental concentrations in NIST standard samples. The consistency between our results with the certified values confirms the validity of the established PIXE analytical technique.

\section{REFERENCES}

[1] S. A. E. Johansson and J. L. Campbell, PIXE: A Novel Technique for Elemental Analysis, 1988, John Wiley and Sons, Chichester and New York, p.96.

[2] J. L. Campbell, D. Higuchi, J. A. Maxwell and W. J. Teesdalale, Nucl. Instrum. Methods B 77 (1993) 95.

[3] Yongqiang Wang and Michael Nastasi. Hanbook of Mordern Ion Beam Materials Analysis Second Edition, 2009, p.237-238.

[4] J. L. Campbell and J. A. Cookson, Nucl. Instrum. Methods B 3 (1984) 185.

[5] Z. Nejedly, J .L. Campbell, W. J. Teesdale, and C. Gielen, Nucl. Instrum. Methods B 132 (1997) 489. 